\title{
HUBUNGAN SCREEN TIME PENGGUNAAN SMARTPHONE DENGAN PERKEMBANGAN SOSIAL ANAK USIA PRASEKOLAH
}

\author{
Hanifah Nofadina ${ }^{1}$, Nur Oktavia Hidayati ${ }^{2}$, Fanny Adistie ${ }^{3}$ \\ ${ }^{1}$ Fakultas Keperawatan, Universitas Padjadjaran \\ Email: hanifah15007@mail.unpad.ac.id \\ ${ }^{2}$ Fakultas Keperawatan, Universitas Padjadjaran \\ Email:nur.oktavia@unpad.ac.id \\ ${ }^{3}$ Fakultas Keperawatan, Universitas Padjadjaran \\ Email: fanny.adistie@unpad.ac.id
}

\begin{abstract}
Excessive screen time can have an impact on the social development delayed of preschool-aged children, preschooler are still in a critical development stage, where they are forming their social identity and building. This study aims to look at the relationship between screen time of smartphone use and the social development of preschoolers. This research was a quantitative descriptive study with correlational design. The population of this study were the parents of TKIT Alam Ash-Shofwah students who had children aged 3-6 years old. The sample in this study were 36 people with a total sampling method. Data was collected using instruments screen time questionnaire and social development assessment on the Denver Development Screening Test (DDST). Data were analyzed using Pearson chi-square to see the correlation between variables, with a significant level $\alpha=5 \%$ (0.05). Based on the results of the study, $52.8 \%$ of children had high screen time and $47.2 \%$ were normal. $58.3 \%$ of children had normal social development and $41.7 \%$ suspect. The results of the chi-square test showed $\rho$ of $0.037<0.05$ and OR of

4.469. It can be concluded that there was a significant relationship with 4.469 times greater chance. It is recommended for parents to limit and monitor screen time of their children as a form of prevention of social delays.
\end{abstract}

Keywords: Preschool; Screen time; Smartphone; Social development

\section{PENDAHULUAN}

Berdasarkan data oleh AdReaction (2014), Indonesia berada diurutan pertama sebagai negara dengan kecanduan smartphone tertinggi di dunia dengan ratarata penggunan 181 menit perhari, diikutioleh Filipina dengan rata-tata penggunaanselama 174 menit dan Tiongkok selama 170 menit perhari. Rentang usia pengguna smartphone pun meluas hingga menjangkau usia muda, sebagian besar anak-anak telah terpapar smartphone tersebut, bahkan anak- anak dalam usia prasekolah. Berdasarkan laporan dari Common Sense Media (2017 dalam Howard, 2017), 42\% dari anak-anak berusia kurang dari 8 tahun telah memiliki gadget sendiri, meningkat sebanyak $7 \%$ dari 4 tahun yang lalu.

The American Academy of Pediatrics (APP) pada tahun 2016 merekomendasikan kebijakan baru mengenai waktu penggunaan media pada anak, dimana anak usia 2-5 tahun dibatasi hanya selama 1 jam perhari dengan program yang high-quality. Waktu screen time yang dibatasi untuk anak usia diatas 2 tahun ditetapkan untuk mencegahkurangnya aktivitas anak (Department of Health of Western Australia, 2019) yang diakibatkan oleh screen time. Anak usia prasekolah berada dalam tahap perkembangan kritis, seperti pembentukan identitas dan membangun sosial (Kardefelt-

DOI : https://doi.org/10.51544/jmn.v4i2.1654

(C) 2021 Jurnal Mutiara Ners. This is an open accessarticleunder the CC BY-SA license

Website : http://e-journal.sari-mutiara.ac.id/index.php/NERS/index 
winther, 2017). Mereka berada dalam periode dimana sebagian besar dari aktivitas melibatkan unsur permainan. Dengan bermain anak dapat meningkatkan kemampuan sosialnya (Izzaty, 2017). Anak usia prasekolah disebut juga dalam higly eventful and uniqe period of life dimana banyak kejadian penting dan unik terjadi yang dapat mempengaruhi mereka diusia lebih besar (Santrock, 2002). Akan tetapi hasil yang didapatkan jika permainan dilakukan hanya satu arah akan bersifat bias, penggunaan smartphone memiliki sifat permainan satu arah, sehingga proses belajar anak menjadi tidak alami (Sari \& Mitsalia, 2016).

Penggunaan smartphone bagi anak-anak bermanfaat dalam meningkatkan kemampuan kognitif, aplikasi interaktif seperti game dan video dapat menjadi tantangan dan sumber edukasi, mengasah skill motorik, serta juga dapat menjadi distraksi bagi anak, menyenangkan, edukatif, dan meningkatkan jiwa kompetitor dalam jiwa anak (Sundus, 2018). Akan tetapi penggunaan smartphone juga memberikan efek negatif yang cukup banyak. Akibat penggunaan smartphone yang terlalu sering dapat memperlambat perkembangan berbicara dan berbahasa anak, dapat menyebabkan attention deficit: Hyperactivity disorder (ADHD), mengacu pada masalah perhatian, aktivitas yang berlebihan atau kesulitan mengendalikan perilaku dan dampak yang paling sering ditemukan adalah pada perkembangan sosialanak. Anak mudah gelisah, tidak fokus, dan mudah teralihkan hingga menyebabkan perubahan perilaku. Penggunaan yang berlebihan juga dapat mengurangi waktu anak untuk bersosialisasi dan belajar,terutama pada toddler yang mana dimasa itu anak-anak banyak belajar dari sosialnya. Selain itu dapat terjadi ansietas, depresi, dan berdampak negatif pada perkembangankarakter anak (Sundus, 2018).
Penulis telah melakukan studi pendahuluan di TKIT Alam Ash-Shofwah yang berlokasi di Desa Cikeruh Jatinangor. TKIT Alam Ash-Shofwah adalah TK reguler dimana proses belajar mengajar dilakukan selama 3 hingga 4 jam perhari selama 5 hari dalam seminggu, sehingga anak memiliki waktu bermain smartphone di rumah lebih besar. Dari studi pendahuluan ini penulis merangkum beberapa anak diberikan akses smartphone masih dalam waktu 1 tahun terakhir, 2 orang anak telah diberi akses sejak usia batita. Beberapa orang tua mengeluhkan anaknya menjadi acuh dan sering tidak menyahut saat sibuk dengan smartphonenya, salah satu orang tua juga mengeluhkan anaknya menunjukkan gejala agresif saat bermain dengan smartphonenya, dan 1 anak yang menangis saat tidak diizinkan bermain smartphone.

Sebagai seorang calon perawat tentu harus memahami dampak positif maupun negatif dari screen time terutama terhadap perkembangan sosial anak. Hal tersebut bertujuan agar dapat meningkatkankesadaran akan peran perawat dalam upaya promitif dan preventif mengenai dampak buruk yang mungkin timbul, salah satunya adalah terjadinya keterlambatan perkembangan sosial pada anak. Serta agar perawat lebih sigap dalam menghadapi isu kesehatan ini, juga mampu berpikir kritis dalam menghadapinya.

\section{METODE PENELITIAN}

Penelitian ini menggunakan pendekatan kuntitatif deskriptif dengan desain korelasional. Populasi pada penelitian merupakan orang tua murid TKIT Alam Ashsofwah Jatinangor dengan metode total sampling sebanyak 36 orang. Data diambil menggunakan kuesioner screen time oleh Maoludin (2018) dan kuesioner aspek perkembangan sosial Denver. Data dianalisa menggunakan metode univariat berupa tabel deskriptif statistik dan bivariat berupa $c h i$

DOI : https://doi.org/10.51544/jmn.v4i2.1654 
square yang terlebih dahulu dilakukan uji normalitas data.

3. HASIL

Setelah dilakukan analisis data didapatkan hasil sebagai berikut :

Tabel 1. Distribusi Frekuensi Screen Time Penggunaan Smartphone pada Anak Usia Prasekolah

\begin{tabular}{ccc}
\hline Sreen Time Penggunaan Smartphone & f & \% \\
\hline Normal & 17 & 47,2 \\
Tinggi & 19 & 52,8 \\
Total & 36 & 100,0 \\
\hline
\end{tabular}

Berdasarkan Tabel 1. diketahui bahwa 19 orang (52,8\%) dari 36 anak memiliki total screen time penggunaan smartphone dalam kategori tinggi dan kategori normal sebanyak 17 orang $(47,2 \%)$

Tabel 2. Distribusi Frekuensi Perkembangan Soaial Anak Usia Prasekolah

\begin{tabular}{ccc}
\hline Perkembangan Sosial & f & \% \\
\hline Normal & 21 & 58,3 \\
Suspect & 15 & 41,7 \\
Total & 36 & 100,0 \\
\hline
\end{tabular}

Berdasarkan Tabel 2. diketahui sebagian besar anak yaitu sebanyak 21 orang $(58,3 \%)$ memiliki perkembangan sosial dalam rentang normal, serta anak dengan perkembangan sosial dalam rentang suspect sebanyak 15 anak (41,7\%).

Tabel 3. Tabulasi Silang Screen Time Penggunaan Smartphone dengan Perkembangan Sosial Anak Usia Prasekolah

\begin{tabular}{|c|c|c|c|c|c|}
\hline \multirow{3}{*}{ Screen Time Anak } & \multicolumn{4}{|c|}{ Perkembangan Sosial Anak } & \multirow[b]{3}{*}{ Total } \\
\hline & \multicolumn{2}{|c|}{ Normal } & \multicolumn{2}{|c|}{ Suspect } & \\
\hline & $\mathbf{f}$ & $\%$ & $\mathbf{f}$ & $\%$ & \\
\hline Normal & 13 & 76,5 & 4 & 23,5 & 17 \\
\hline Tinggi & 8 & 42 & 11 & 58 & 19 \\
\hline
\end{tabular}

Berdasarkan tabel (4.1.5.1), terlihat hasil uji normalitas kormogorov-smirnov adalah sebesar 0,864 > 0,05 yang berarti data berdistribusi normal. Analisis hubungan antara screen time penggunaan smartphone dengan perkembangan sosial anak usia prasekolah diperoleh hasil bahwa 11 orang (58\%) dengan screen time sering mengalami perkembangan sosial suspect, sedangkan anak dengan perkembangan sosial normal sebanyak delapan orang (42\%). Anak yang memiliki screen time normal cenderung

DOI : https://doi.org/10.51544/jmn.v4i2.1654

(C) 2021 Jurnal Mutiara Ners. This is an open accessarticleunder the CC BY-SA license Website : http://e-journal.sari-mutiara.ac.id/index.php/NERS/index 
memiliki perkembangan sosial normal, dimana perbandingan anak dengan perkembangan sosial normal dengan suspect sebesar 13:4 orang (76,5\%: 23,5\%).

\section{PEMBAHASAN}

Berdasarkan hasil penelitian ini, jumlah anak yang memiliki screen time penggunaan smartphone tinggi adalah sebanyak 19 dari 36 orang anak atau sebesar $52,8 \%$, sedangkan anak dengan screen time penggunaan smartphone normal hanya berjumlah 17 orang $(47,2 \%)$. Kategori screen time yang tinggi pada anak prasekolah berdasarkan rekomendasi oleh Australian Goverment Department of Health (2017) dan The American Academy of Pediatrics (2016) adalah lebih dari 60 menit dalam sehari. Banyak penelitian telah dilakukan menunjukkan dampak negatif akibat penggunaan yang berlebihan, seperti beberapa masalah kesehatan, kejadian obesitas, masalah emosional, rentang perhatian pendek, keterlambatan berbicara, pola tidur yang buruk, serta keterlambatan perkembangan (Berry, Stewart, \& Walker, 2019).

Resly (2018) menjelaskan bahwa orang tua yang memberikan gadget dengan tujuan tertentu tanpa adanya pengawasan memiliki dampak negatif yang cukup besar pada anak. Kejadian screen time yang tinggi pada anak adalah hasil interaksi anak dan orang tua, yang diperngaruhi oleh sikap dari orang tua tersebut. Penelitian menyebutkan bahwa dengan mengontrol anak menggunakan screen time, seperti mengizinkan anak mengakses gadget untuk menenangkan atau sebagai bentuk reward akan meningkatkan ketertarikan anak akan elektronik yang diaksesnya. Akibatnya anak menjadi biasa dengan penggunaan smartphone dalamdurasi lama dimana screen time dapat meningkat hingga 20 menit (Lauricella, Wartella, \& Rideout, 2015; Tang et al., 2018).
Sebanyak 21 orang $(58,3 \%)$ anak memiliki perkembangan sosial normal. Kemungkinan perkembangan sosial anak lebih baik dapat disebabkan juga oleh pekerjaan orang tua. Hal tersebut berhubungan dengan pemantauan anak oleh orang tua, jika orang tua lebih banyak dirumah maka anak akan lebih terpantau dibandingkan orang tua yang bekerja diluar. Hasil tersebut sejalan dengan penelitian Sujianti (2018), menyebutkan bahwa kemungkinan perkembangan tidak baik sebanyak 49.1 persen adalah karena karakteristik pekerjaan responden kebanyakan bekerja.

Setelah dilakukan uji Pearson Chi Square ditemukan hasil bahwa nilai $\rho$ value lebih kecil dari batas kritis $(\alpha)$ yaitu sebesar 0,037 $<0,05$. Karena itu dapat disimpulkan bahwa Ha diterima, sehingga dapat diartikanbahwa terdapat hubungan yang signifikan antara screen time penggunaan smartphone dengan perkembangan sosial anak usia prasekolah. Hasil ini sejalan dengan Marsal dan Hidayati (2017) yang menunjukkansmartphone dapat berpengaruh sebesar 40,2\% terhapat perkembangan sosial anak. Screen time yang tinggi memilik dampak pada tumbuh kembang anak (Maharani, 2016). Penelitian oleh Madigan et al, (2019) menunjukkan bahwa screen time yang lebih besar pada anak usia prasekolah memiliki skor lebih rendah pada tes skrining perkembangan. Penelitian oleh Heni dan Mujahid (2018) pun menunjukkan adanya hubungan signifikan antara durasi penggunaan smartphone dengan perkembangan sosial. Hasil penelitian tersebut menunjukkan $62,5 \%$ perkembangan sosial anak tidak sesuai adalah anak yang menggunakan smartphone dalam durasi sering.

DOI : https://doi.org/10.51544/jmn.v4i2.1654

(c) 2021 Jurnal Mutiara Ners. This is an open accessarticleunder the CC BY-SA license Website : http://e-journal.sari-mutiara.ac.id/index.php/NERS/index 
Uji odd-ratio (OR) menunjukkan nilai estimasi sebesar 4,469 dan nilai syimp. Sig (2-sided) $0,042<0,05$, sehingga dapat diartikan bahwa terdapat korelasi yang kuat antara kedua variabel dan menyimpulkan bahwa perkembangan sosial anak dengan screen time dalam jumlah tinggi 4,469 kali lebih besar peluang adanya keterlambatan perkembangan sosial dibandingkan anak dengan screen time normal, yaitu tidak lebih dari satu jam dalam sehari. Hasil ini berbanding terbalik dengan hasil Sujianti (2018) yang menunjukkan tidak adanya perbedaan secara statistik, serta nilai peluang hanya sebesar 1,467 kali. Perbedaanhasil ini dapat terjadi karena adanya perbedaan karakteristik orang tua, pada penelitian tersebut peneliti menyebutkan bahwa mayoritas orang tua adalah orang- orang yang memiliki matang secara psikologis sehingga memiliki pemahaman mengenai merawat dan mengasuh anak.

\section{SIMPULAN}

Berdasarkan penelitian ini dapat disimbulkan bahwa:

1. Sebagian besar screen time penggunaan smartphone adalah dalam durasi tinggi pada anak usia prasekolah di TKIT Alam Ash-sofwah Jatinangor adalah sebanyak 19 orang $(52,8 \%)$.

2. Sebagian besar perkembangan sosial anak usia prasekolah di TKIT Alam Ashsofwah Jatinangor di interpretasikan normal dengan jumlah 21 orang $(58,3 \%)$.

3. Hasil uji korelasi menunjukkan $\rho$ value $=0,0357>\alpha=0,05$, yang dapat diartikan bahwa ada hubungan yang berarti antara screen time penggunaan smartphone dengan perkembangan anak prasekolah di TKIT Alam Ash-sofwah Jatinangor.

4. Nilai $\mathrm{OR}=4,469$, menunjukkan bahwa anak dengan screen time tinggi memiliki peluang 4,496 kali lipat lebih besar memiliki perkembangan suspect.

\section{REFERENSI}

AdReaction. (2014). Global report. London: MillwardBrown. Retrieved from www.midlwardbrown.com/adreactio

Berry, S., Stewart, T., \& Walker, C. (2019). Effects of screen time on preschool health and development. Wellington: Ministry of Social Development.

Department of Health of Western Australia. (2019). Screen time. Retrieved March 7, 2019, from https://www.healthywa.wa.gov.au/Artic les/S_T/Screen-time

Howard, J. (2017). Kids under 9 spend more than 2 hours a day on screens, report shows. Retrieved December 11, 2018, from

https://edition.cnn.com/2017/10/19/heal th/children-smartphone-tablet-usereport/index.html

Izzaty, R. E. (2017). Perilaku anak prasekolah. Jakarta: Gramedia. Retrieved from https://books.google.co.id/books?id=yC 9IDwAAQBAJ\&pg=PA116\&dq=defini si+prasekolah\&hl=id\&sa=X\&ved $=0 a h$ UKEwjTxvXMzKnfAhWFWX0KHR_ WCEcQ6AEIKTAA\#v=onepage $\& \mathrm{q}=\mathrm{de}$ finisi prasekolah \&f=false

Kardefelt-winther, D. (2017). How does the time children spend using digital technology impact their mental wellbeing, social relationships and physical activity? An evidence-focused literature review, (December).

Lauricella, A. R., Wartella, E., \& Rideout, V. J. (2015). The complex role of parent and child factors. Journal of Applied Developmental Psychology, 36, 11-17. https://doi.org/10.1016/j.appdev.2014.1 2.001

Maoludin, D. (2018). Gambaran screen time

DOI : https://doi.org/10.51544/jmn.v4i2.1654

(C) 2021 Jurnal Mutiara Ners. This is an open accessarticleunder the CC BY-SA license Website : http://e-journal.sari-mutiara.ac.id/index.php/NERS/index 
pada anak usia pra sekolah 4-6 tahun di Taman Kanak-Kanak Khas Mesjid Agung Garut. Universitas Padjadjaran.

Resly, I. V. (2018). Hubungan screen time dengan perkembangan sosial anak. Universitas 'Aisyiyah.

Santrock. (2002). Life-span development. Jakarta: Erlangga.

Sari, T. P., \& Mitsalia, A. A. (2016). Ppengaruh penggunaan gadget terhadap personal sosial di TKIT Al Mukmin. Profesi, 13(2), 72-78.

Sundus, M. (2018). The impact of using gadgets on children. Journal of Depression and Anxiety, 7(4), 1-3. https://doi.org/10.4172/21671044.1000296

Tang, L., Darlington, G., Ma, D. W. L., Haines, J., Family, G., \& Study, H. (2018). Mothers' and fathers 'media parenting practices associated with young children 's screen-time : a crosssectional study, 5(37), 1-10.

The American Academy of Pediatrics. (2016). American academy of pediatrics announces new recommendations for children's media use. Retrieved November 11, 2018, from https://www.aap.org/en-us/aboutthe-aap/aap-pressroom/Pages/American-Academy-ofPediatrics-Announces-NewRecommendations-for-ChildrensMedia-Use.aspx

DOI : https://doi.org/10.51544/jmn.v4i2.1654

(C) 2021 Jurnal Mutiara Ners. This is an open accessarticleunder the CC BY-SA license Website : http://e-journal.sari-mutiara.ac.id/index.php/NERS/index 